Fecha de recepción: mayo 2014 Fecha de aceptación: mayo 2015 Versión final: julio 2016
Nuevos soportes, nuevos cuerpos

Gabriela Gómez del Río *

Resumen: La intervención de la tecnología ha modificado algunos aspectos de la vida diaria, en particular la forma en la que se accede al conocimiento; en las zonas más urbanizadas el fenómeno se produce a través de la pantalla digital. De un tiempo a esta parte, se han instalado nuevos hábitos de consumo que han cambiado la manera en la que se conoce y se reproduce el mundo. El sujeto se reubica desde otra perspectiva, modificando incluso el modo de percibirse a sí mismo. Pareciera que el cuerpo ha comenzado también a virtualizarse. El circuito de la moda no queda fuera de estos cambios, y es a través de sus producciones que puede identificarse este fenómeno. En este artículo se analizan los cambios sobre la representación del cuerpo en las producciones de moda locales a partir del análisis de la revista Para Ti Colecciones.

Palabras clave: Moda - producción - comunicación - digital - online - cuerpo - virtual fotografía - consumo.

[Resúmenes en inglés y portugués en las páginas 216-217]

${ }^{(*)}$ Licenciada en Ciencias de Comunicación (UBA), especialización en procesos educativos. Diseño de Modas, especialización en Moldería (Donato Delego). Docente en la Universidad de Palermo en el Departamento de Investigación y Producción de la Facultad de Diseño y Comunicación. Es docente en otras instituciones en diferentes niveles de asignaturas de modas y experimentación.

Muchas pueden ser las razones que permiten afirmar que la representación del cuerpo, en las producciones gráficas de moda contemporánea, ha variado. A través del desarrollo de este escrito se analiza los cambios que se pueden identificar sobre la representación del cuerpo en las producciones de moda locales teniendo como paquete textual de análisis ejemplares de la revista Para Ti y Para Ti Colecciones.

Como eje del análisis se entiende que desde el año 2000, la irrupción del internet comienza a proyectar una imagen híbrida que se suma a relación que ya había consumado la imagen fija de la gráfica, la imagen móvil del cine, y la imagen electrónica de la televisión. Sexe, (2007) La audiencia ahora devenida en usuarios se construye, cuestión que exige a los medios una alfabetización constante en relación a sus propios códigos. Toda inclusión de un nuevo medio exige la ampliación del marco de referencia que se tenía hasta el 
momento de su aparición, como señala Huergo (1997) los medios sumados a las nuevas tecnologías estarían provocando una alfabetización múltiple, que se compone de dos fases: leer medios y producirlos.

El contrato de lectura entre Para Ti Colecciones y su lectora desde su primera publicación en el año 2005, se ha ido acomodando a los cambios a los que ambas partes se vieron expuestas con la inclusión de las nuevas tecnologías a lo largo de la historia. La lectora, actualmente, se ve intervenida por varios soportes que emiten información a los que accede en simultáneo, y en los que ella también puede generar información al mismo tiempo. Es decir que, este cambio ha variado la forma de consumo, circulación y se producción de los medios. La contemporaneidad entendida como un "periodo líquido" siguiendo a Bauman, articula un contexto propio para que ante la intervención del cuerpo bajo estos parámetros los medios gráficos busquen la identificación de un público comprendido como nativo de la web, según Piscitelli. Por lo tanto, la producción de moda gráfica contemporánea buscaría a través de su modalidad de representación la identificación con cuerpos que se comprenden a sí mismos como cuerpos reales tanto en la interacción del mundo físico como en el mundo online.

\section{Otros soportes, nuevos cuerpos}

La imagen hibrida del cuerpo que comienza a proyectarse en el año 2000 en relación a las imágenes ya establecidas dadas por los medios anteriormente recrea y exige la ampliación del marco de referencia y pone a rodar como explica Huergo (1997) procesos como el de la alfabetización múltiple, que se compone de dos fases: leer medios y producirlos. A estas nuevas modalidades las ha denominado alfabetizaciones posmodernas, que producen en relación a la estructuración de la percepción, una suerte de dislexia -concepto que retoma de McLuhan frente a la crisis de la lógica escritural- o incapacidad de adoptar un único y fijo punto de vista con respecto a la realidad. Vale aclarar que la conceptualización "posmoderno" como señala Sloterdijk remite a un concepto poco claro que podría darse a una confusión al menos teórica. "La expresión 'posmoderno' me parece estéril, señala exclusivamente una zona donde termina el estado de alerta intelectual: 'Atención, aquí empieza una zona libre de análisis"' (Sloterdijk, 2003, p. 168) Este vacío de argumentación sobre la conceptualización que surge de este contexto se cristaliza ante las características del mismo, dándole al análisis también un relato fragmentado.

Tanto los medios como las nuevas tecnologías provocarían nuevas formas de conocimiento, se produce algo así como una pedagogía perpetua, que implicaría estar no recortada, ni organizada y controlada por la escuela. (Huergo 1997). La era digital estallaría la linealidad de lectura que hasta entonces se poseía, no sólo expandiendo sus límites sino exigiendo nuevos hábitos, porque como señala Sibilia "nacen nuevas formas novedosas de ser y estar en el mundo" (2008, p. 33). Se expone al cuerpo ante una nueva relación con el espacio que le exige replantarse la manera de entenderse, comunicarse, construirse y reproducirse. 


\section{Para ti, un espacio}

Como se mencionó anteriormente, la inclusión de nuevas tecnologías exige una ampliación del marco de referencia, también en el ámbito social, es decir, que esta irrupción invade la vida en sí de sus usuarios. Ortopediza y coerciona cada una de las acciones que se realizan en la vida cotidiana, y por ende reedita el modo en el que el cuerpo aprende y se desplaza por el espacio que hasta la inclusión de nueva tecnología transitaba.

La escuela como institución de la reproducción de la cultura dominante, y por ende legítima, tiene un rol fundamental ante el modo en el que se reproduce el conocimiento nuevo, aunque sea por oposición a éste. Lo que se enseña en la escuela no tiene una razón de ser propia, es decir, no es independiente de lo que sucede en otras dimensiones sociales relevantes de la vida social, porque lo que se enseña en las instituciones escolares tiene un sentido fuera de las escuelas, es decir, en la sociedad como un todo (Tenti Fanfani, 2001). El espacio que impone la publicación especializada y el modo en el que elige construir el relato de la moda no puede estar por fuera de la red social en la que se encuentra inmersa la lectora que habita la revista.

La actualidad marca que la predominancia de la imagen acarrea un cambio significativo, porque como señala Sibilia (2008) coloca al cuerpo ante una nueva forma de ser y estar en el mundo. La ampliación del marco de referencia ante la introducción de nuevos modelos audiovisuales y tecnologías digitales como el internet produce más que un movimiento un descentramiento, es decir que, produce un conjunto de procesos y experiencias que testimonian la expandida circulación por fuera del libro de saberes socialmente valiosos, como señala Barbero (2000), des-ubican y des-centran el saber que hasta su aparición reinaba entre el espacio escuela y el tiempo del aprendizaje escolar. Esta característica fragmenta la modalidad de lectura exigiendo nuevas competencias que deberá poseer su lector. Porque, la inclusión de la nueva tecnología y modelos audiovisuales no poseen la novedad en los aparatos que los portan sino en la exigencia que le propinan a sus usuarios haciendo que éstos deban variar su percepción y lenguaje, a nuevas sensibilidades y escrituras.

Este fenómeno que implica un descentramiento de hábitos arraigados por más de cinco siglos, implicaría pensar, señala Barbero (2000), en un nuevo paradigma. El cambio más desconcertante para el racionalismo, con el se identificó la primera modernidad, es el que introduce el nuevo estatuto cognitivo de la imagen. Al estar frente a otra figura de razón, Barbero (2003), promueve la necesidad de pensar la imagen desde una nueva configuración sociotécnica, porque los nuevos dispositivos como la computadora no sería sencillamente un instrumento con el que se reproducen objetos sino que implicaría un nuevo tipo de tecnicidad que posibilita el procedimiento de informaciones, y cuya materia prima son abstracciones y símbolos. Poder analizarlo desde esta otra perspectiva inaugura una nueva aleación de cerebro e información que sustituye a la relación exterior del cuerpo con la máquina.

Este nuevo paradigma de pensamiento estaría rehaciendo las relacionas que se dan entre el orden de los discursivo (la lógica) y de lo visible (la forma), de la inteligibilidad y sensibilidad respectivamente. Barbero (2003) asevera, entonces, que este nuevo estatuto cognitivo de la imagen, que implicaría pensar en un nuevo paradigma, se produce a partir de su informatización. 
Las lectoras nativas online, de los últimos años, a la que evocaría Para Ti, y que luego acotaría aún más mediante Para Ti Colecciones, pertenecería a la sociedad de la Tercera Fase como señala Simone (2001), esta conceptualización remite al cambio vigente de los parámetros en la sociedad tradicional que implica la creación y difusión de los conocimientos. El recorte sugiere dos tipos de lógicas, una proposicional que implicaría un carácter analítico, y otra no-proposicional que alude a una actitud genérica que se limita a evocar los elementos propios del contenido de manera global, vaga desde el punto de vista referencial, en general no nombra las cosas sino que se alude a las mismas con conceptualizaciones generales, rechaza la estructura sin utilizar jerarquías dejando a su interlocutor que construya las suyas propias. Estas nuevas generaciones construyen su cotidianeidad mediante la cultura del zapping, producto de una alfabetización múltiple que excede a las paredes del espacio escuela.

\section{Para Ti Colecciones: cuerpos a su máxima expresión}

En la primera publicación de Para Ti Colecciones (Ver Figura 1) los editores señalan con orgullo las 500 páginas que la lectora podrá disfrutar al igual que podía hacerlo mediante las publicaciones especializadas internacionales como Elle o Vogue. La publicación aparece dos veces al año y enseña mediante el relato que construye cuáles serán los parámetros que la moda seguirá en nuestro país. Por supuesto que, la información que la revista presenta dejó de serlo en relación a lo que se entiende en el campo como tendencia, y sí se podría entender que lo nuevo remite a las característica que presenta el relato que construye en base a las marcas nacionales. Porque, por ejemplo, la publicación que se presenta en el mes de Abril recorta la temporada de invierno de ese año, información que se presentó en las capitales de moda mediante los desfiles meses antes, y a la que los interesados ya pudieron acceder mediante los diferentes portales que levantan este tipo de información en sitios web referentes del sector.

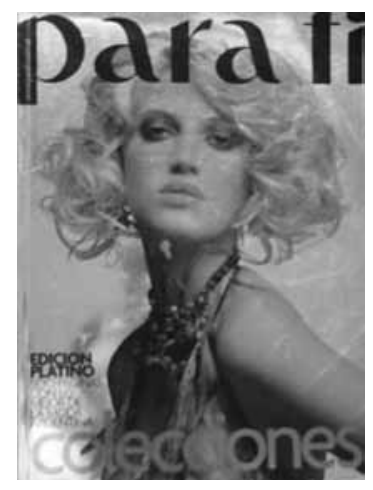

Figura 1. Primera tapa Para Ti Colecciones, $\mathrm{N}^{\circ}$ 4316, 8/4/2005. Fuente. Revista Para Ti. 
Lannelongue (2008) señala que el desfile, y sobre todo los de pret- a porter listo para llevar es un momento importante para la industria de la moda porque lo que en ellos se pueda ver será supuestamente lo que la compradora podrá capturar en las tiendas -y no sólo de ropa-, pero hasta antes de llegar ahí la colección tiene algunos pasos previos imprescindibles para la industria. La información primera sobre los desfiles comienza a fragmentarse, y hasta en ocasiones llega a quemarse, porque ya no es necesario esperar a que la información aparezca publicada con cierta traducción sobre lo vendrá, la web la sirve al instante.

\section{De producciones y avisos}

Para ti Colecciones, entonces, representaría la exacerbación de uno de los eslabones mencionados dentro del circuito de la moda. Para construir el relato de la moda, la publicación, segmenta por categorías al conjunto indumentario que presentará a su lectora. Las categorías que se resaltan a modo de carátula introductoria a las diferentes producciones temáticas se relacionan con la tendencia del momento, en su primer número se han acotado ocho categorías: estampa, colores, estilos, ítems, accesorios, texturas, abrigos, noche. Estas categorías son primero enunciadas por página, que puede leerse de modo horizontal, en donde ha montado una serie de imágenes de desfiles internacionales. Parte de la estrategia es mostrarle a la lectora la tendencia que la publicación ha seleccionado de la presentación primera de las marcas y creadores internacionales. Luego la revista recreará en sus producciones la tendencia pero, en mayoría, con marcas nacionales. Aquello que le muestra mediante marcas como Versace o Kenzo, para la lectora desde una perspectiva nacional se consigue con Akiabara, Wanama o Paula Cahen d'Anvers, así automáticamente la publicación pareciera aplicar aquello que le viene propinando a su lectora promedio: una manera más de acceder a ese estilo legitimo de manera accesible para ella, pero que en el mejor de los casos para la partes involucradas en este contrato, la lectora sólo accederá a la publicación.

Los avisos publicitarios, parecieran estar a la par de las producciones de moda. En las revistas la relación entre publicidad y producciones sería uno a uno, es decir que por cada hoja de publicidad puede generarse una página de producción. En este número los avisos ocupan un $47,8 \%$ en relación al $43,4 \%$ que ocupan las producciones de moda. La mención de marca comienza a rodar dentro del circuito que propone la revista que va entre su publicidad, mención en secciones, y en las producciones de moda.

Entonces, ante el recurso publicitario de la repetición de las marcas de los objetos que se muestran, la revista pone manifiesto su estrategia pedagógica que traduce el contenido para su público lector devenido en consumidor al que se le da como rasgo característico principal, el precio y la marca de cada producto como únicos datos. 


\section{La imagen sobre la palabra}

A partir del análisis realizado sobre la relación entre la palabra y la imagen en la publicación, que recorta los últimos cincuenta años, se pudo detectar que Para Ti logra, incluyendo una publicación nueva mediante, despojarse de casi el $94 \%$ de palabras para describir la moda a sus lectoras, acotando así la traducción que entre ambos conjuntos la lectora debía generar ante el relato de la moda que la publicación presenta en su espacio. Este porcentaje permite observar la modificación que hubo con respecto al contenido de la enseñanza que la publicación reproduce como legítimo.

Sibilia postula que a partir de 1980 se exacerba un fenómeno que implica al campo biotecnológico en donde un número significativo de empresas en crecimiento dominan un mercado global que implican millones de dólares. Las empresas responden a las investigaciones de mercado quienes dictan sus producciones, esto genera una fuerte dependencia a lo que se denominó tecnociencia. Esto implicó que:

...las nuevas tecnologías de formateo de cuerpos y almas ya no apuntan de forma exclusiva o prioritaria a los ciudadanos de los Estados. El foco de esas estrategias está compuesta por consumidores, ya no distribuidos en poblaciones nacionales o censos demográficos, sino segmentados en términos estrictamente mercadotécnicos (Sibilia, 2005, p. 227).

La relación enseñanza-aprendizaje que planteó en primer momento Para Ti ha sido intervenida entonces por la supremacía que fue obteniendo el mercado (el Soberano, como lo denomina Bauman) durante el periodo señalado en el análisis. Es decir que, la lectora de esta publicación, como se mencionó anteriomente, pareciera haber pasado a ser concebida primero como consumidora y luego como lectora/alumna como en un inicio. Esta particularidad no modificaría el contrato de lectura planteado porque si bien puede haber variado la metodología didáctica con la que enseña el contenido en sí, el objetivo sigue siendo el mismo: enseñar a sus lectoras eso que ellas están deseosas de saber.

\section{Cada período su cuerpo}

La publicación ha construido de diferentes maneras a su lectora promedio, para esto ha recortado el cuerpo y el estilo legítimo que debía mostrar y reproducir en cada una de las décadas. La publicación ha acotado a la mujer promedio utilizando el recurso económico de la estereotipización que puede delimitarse a partir del análisis realizado sobre sus tapas durante los años setentas, ochentas, noventas y los denominados 2000. 


\section{Los ángeles de tapa}

Para los años setentas resume al cuerpo femenino aludiendo a una de las series norteamericanas más populares de la época: Los ángeles de Charlie. Señala que en este periodo el look se suaviza, en relación a décadas anteriores, lo que implicaría que lograrlo es más complejo porque la mujer debía poder lucir natural mediante una gran producción. Se disminuye el maquillaje, ya no se llevan las pestañas tan cargadas (como marcaba el estilo Twiggy) y se utilizaba el párpado limpio con sobras pero en un solo tono. El estilo se basaba en iluminar la mirada. Siempre debía lucir joven. Un referente de la época también fue otra figura de la tele, Farrah Fawcet quien dejó como huella de este periodo a su peinado batido con un toque de frisé-como señala la publicación al definirla. En la tapa que el número emplea como referente sugiere dos cosas, primero que la tele se había consolidado, y segundo que había que vender el contenido mediante los títulos que podían incorporar en la misma, porque la zona de competencia lo exigía. Se puede ver el título de la revista entrelazado con la parte superior de la modelo, que se ubica en pose medio perfil sonriente sobre el margen derecho, en contra punto y equilibrando la imagen se encolumnan títulos de venta como "Los amores, su carrera, su futuro Mirtha Legrand: La pura Verdad", "Tortas y Masitas para invierno, por Doña Petrona”, “QQué hacer con su hijo en vacaciones?”, y se anuncia que de regalo tiene para su lectora un "Súper póster de Rodolfo Beban". En la tapa se hace referencia a tres figuras que en ese momento se desenvolvían en distintos programas dentro de la grilla televisiva. Las figuras de la tele también se convertirían en modelos a seguir junto a las mannequis.

\section{Chicas diez}

En los ochentas la publicación delimita al cuerpo femenino de la época a partir de descripción de su superficie: la furia del color. La actitud que tomaría el cuerpo ya no sería de conquista a través de la utilización de la insinuación, sino que estaría continuamente llamando la atención a partir de su estado furioso gobernado por los colores que en ese periodo se implementaron. Los colores se utilizaban en igual medida desde el maquillaje hasta los zapatos. Las sombras brillosas debían ser violetas, azul francia, fucsia, y se aplicaban generando una mirada atigrada que remitiera a la furia que debía trasmitir. Los referentes de la época remiten a la exacerbación del cuerpo a través de la gimnasia, ya no era importante que luciera saludable, sino que debía verse atlético. La Lycra ${ }^{\circledR}$ había aparecido como novedad y entonces las prendas debían verse adherentes al cuerpo, y éste debía ser contorneado por el trabajo deportivo, ya no eran válidas las prendas de primera piel como el corsé. Las modelos a seguir fueron, en el comienzo de la década, Bo Derek quien complejizó el estilo obligando a sus seguidoras a no solo torsionarse el pelo para lograr el peinado que se basaba en trenzas, sino que debían esculpir su cuerpo a diario para cumplir socialmente con el cuerpo legitimo al que habían congraciado - para desgracia de 
muchas- con un diez. La tapa que se muestra como referente presenta a una modelo que luce el típico peinado de trenzas citado anteriormente, su rostro se ve cercado por títulos. Puede verse el de la misma publicación que presenta solo su contorno y que dentro de las letras puede también leerse la fotografía de tapa; también pueden leerse títulos de venta ubicados en paralelo al rostro de la fotografía de tapa como Los diez puntos clave de la moda de invierno, Suplemento especial: Cocina para un mes ahorre entre $\$ 4000$ y $\$ 8000$ por día, luego aparece un título transversal al rostro a la altura del cuello en fondo gris en donde puede leerse Una mujer inválida tardo 12 años en ser indemnizada $i$ Es ineficiente la justicia Argentina? Esta década esta signada por dos eventos que aunque disímiles en relevancia han marcado al periodo: la vuelta a la democracia -luego de ocho años de veda democrática en manos de gobiernos de facto en donde el terrorismo encontró su lugarcon el candidato del partido radical electo democráticamente en el año 1983 presidente de los argentinos Don Raúl Alfonsín. Por otro lado, a dos años de su asunción el Presidente anuncia un nuevo plan económico denominado Plan Austral. Es ese momento, cambió el nombre de la moneda argentina de Pesos a Australes, desde ese momento un austral equivaldría a \$1000. Tras las marcas de agotamiento del plan impuesto en el año 1986, al año siguiente Alfonsín daría por terminada la medida aunque la moneda seguía denominándose de la misma manera y tanto la inflación como déficit interno y externo serían los puntos más álgidos y relevantes para el gobierno. Parecía como si de alguna manera debía quedar atrás - como fuera- el pasado, y vedar los problemas que traía el presente. La industria de la moda debía seguir funcionando y generar recursos de dónde fuera posible para que esto pudiese suceder. Hasta medidos de la década se produce, en el campo de la moda, un fenómenos que podría entenderse como la explosión de las modas sin ideología, se celebran las figuras que surgían de las series y televisivas y la música como Dallas y Dinastía, la música de Duran-Duran, Madonna y Boy George respectivamente. El punto culminante de este fenómeno estuvo signado por el pensamiento posmoderno y el fin del punk Saulquin (2006).

\section{Menos en más}

En los noventa, parecía que la furia de los ochentas había quedado un siglo atrás. La publicación recorta al cuerpo de este periodo bajo el nombre de minimalismo, concepto que se emplea para definir cualquier cosa que haya sido reducida a lo esencial, es decir que, remite a que menos es más. Se define como un look mucho más urbano, tal vez haciendo alusión a la estandarización de la forma sin variaciones significativas. En donde la sobriedad pareciera ser la premisa sine qua non. El maquillaje debía ser marrón y beige opacos en ojos y labios, pero la publicación advierte que nunca en ambos lados al mismo tiempo. El cabello debía verse lacio carré. En nuestro país, un referente de este estilo de peinado fue la modelo Araceli Gonzalez, quien en una publicidad que realizó para la marca CareFree -empresa líder en productos femeninos que eligió a Araceli como imagen a final de los años ochentas- se mostraba con este corte de pelo como signo distintivo de su belleza. La 
publicación hace una advertencia sobre este periodo, y la misma se base en que al margen del corte que se eligiese el cabello debía lucir siempre lacio. Para Ti denomina a la planchita (máquina que puede manipularse para planchar el pelo) como un estandarte de este periodo. La tecnología comienza a incorporarse en la vida diaria como una prótesis del cuerpo que ya no solo debería cumplir con los cánones de la época, sino que debía cumplimentarse con las nuevas tecnologías para lograrlo. En la tapa de la publicación aparece la modelo Claudia Shiffer, quien fue el estandarte, en la época, de un grupo de modelos internacionales que ya no sólo eran modelos sino que las habían transformado en súper modelos; en el grupo también se encontraban Naomi Campbell, Eva Herzigova, y Linda Evangelista. La publicación releva la importancia de la figura que expone, en su tapa, cediéndole el espacio que comúnmente ocupa la palabra Para se puede ver descubierto el rostro de la modelo seguido de pronombre Ti. El número apuesta, entre otros temas, a la figura de tapa para su venta y exhibe títulos como Claudia Schiffer con nosotras: Indiscreciones de la más linda, Alimentos, cremas y consejos: combata la celulitis y la flacidez, Recetas y claves: la cocina anticolesterol, Especial deco: soluciones para problemas difíciles. A la adaptación que el cuerpo de este periodo debía someterse ya no le bastaría con plantearse accesible como dictaban los años setentas, o deportivo como exigían los aerobics de los años ochenta, ni sumarle las nuevas tecnologías como prótesis, sino que debería cambiar sus hábitos alimenticios que poco tenían que con las recetas de crema y algo más que Doña Petrona le había enseñado por años, debía aprender sobre la comida light, es decir sobre los alimentos que no lo eran tales para así tratar de mantenerse en el estado que por definición es imposible: joven.

\section{Todo vale}

En el periodo denominado como los "2000" la publicación define al cuerpo ya no como un continuo de un estilo específico como lo fue haciendo a lo largo de las tapas analizadas, en este periodo construye al cuerpo legítimo como la sumatoria de, denominando al periodo como: vintange. La publicación, describe que a comienzos del siglo XXI hubo un intento de imponer un look, pero los estilos que se impusieron fueron los revivals, que implicaban interaccionar estilos que habían estado vigentes entre la década del cincuenta y los años ochentas. Si bien la publicación ubica a este cuerpo como propio del siglo XXI, sería prudente remarcar que como en el siglo XX la Primera Guerra Mundial había marcado su inicio, aún no podría aseverarse el final de éste, y por ende el inicio del siguiente. Las modas, explica Saulquin 2006, que quedan como marcas de cada periodo podrían definirse como recibientes, porque siguen un ciclo que se repite cada 20 años. Es decir que, los denominados clásicos una vez que han cumplido la secuencia de seis años, se diluyen y vuelven dos décadas más tarde. Estos ciclos dilatados incorporan entre sus seguidoras a una nueva generación, actuando, tal vez, el proceso de identificación entre madre e hija. Los recursos de la historia, la lengua y la cultura tienen que ver con el de las identidades, y lo que éstas hagan de dichas categorías. Implica un proceso de devenir y no de ser, porque 
sugiere en qué podría convertirse el sujeto y no en quién es, o de dónde viene, cuestión esta que atañe a la moda, y cómo esta podría representarse. Las identidades se construyen dentro de la representación y no fuera de ésta, porque se construyen dentro del discurso y no fuera de éste, porque es la diferencia lo que construye las identidades y no aquello que pudiese entenderse al margen de ésta (Hall, 2003). La tapa que la publicación señala como referente de este periodo -aún no culminado-, presenta a una modelo que simula desnudez, con sus ojos remarcados en todos plateados y azules. Su cara se puede ver detrás del título de la publicación, y está compensado visualmente por otros textos que se ubican a su derecha, a su izquierda, y en diagonal. La publicación comienza a incorporar objetos que presenta a su lectora como regalos, en este caso le obsequia a su lectora por el mismo precio de $\$ 5.90$, cuestión que notablemente se resalta en tapa -precio que se ubica sobre un rombo color rojo-, una agenda para que la lectora pudiese ordenar la actividad primordial que implica el mercado de la moda, y sobre todo para estar a la moda: comprar. En el título, en relación al regalo de una agenda, pude leerse con ordenador de compras mensuales, direcciones exclusivas de moda, belleza y deco, y teléfonos útiles. La mejor agenda para la mujer. Entonces, la publicación no sólo presenta en sus páginas aquello que le interesa a la mujer, sino que le facilitaba a su lectora una cuadricula, con la información adecuada, para que ésta reproduzca y registre para no olvidar aquello que es la moda. También puede leerse Pareja en vacaciones: cómo recuperar el sexo perdido, Cocina astrológica: recetas. El cuerpo femenino pareciera estar de vuelta del ciclo que en los sesenta se denominaba como conquista, porque una vez cumplido el ciclo, es decir que se haya exteriorizado a su máxima expresión su actividad socialmente construida como más intima, conceptos como aburrimiento y rutina aceleran y sirven como argumento para cualquier transformación que no sólo se logra mediante la ingesta de alimentos naturales y dormir mejor. Había llegado el momento preciso para que aquello que se oculta se hiciese público, y sea un elemento más del conjunto indumentario, acceder a un nuevo busto, o a un nueva boca parecía ser tan o más cool que presentar un cuerpo enfundado en un traje de la marca más reconocida del momento. Sexe (2007) señala que durante este periodo en donde se ha construido una naturalidad superficial, la subjetividad de la superficie corporal y de las telas es ganada por una sustancia química como la silicona. Entre ambas superficies, además deben parecer producir la sensación de ser naturales, jóvenes y elásticas. Construyéndose así una naturalidad artificial.

Entonces, el cuerpo que evoca los denominados " 2000 " delimita una silueta compuesta de diversos fragmentos propios del ciclo del mismo relato de las modas que encontraron como modo de adhesión entre sí a las características propias del periodo. La gramática que construye al relato del cuerpo en este periodo no excluye el ritmo que implica y distingue a la gramática que impera, y que se alimenta del zapping, desembocando en un hipertexto Barbero, 2000, que exige para poder leerlo una perspectiva que involucra poder aceptar la contextura de un nuevo paradigma. 


\section{La pantallización del cuerpo}

El análisis marca que la imagen cobra relevancia en relación al resto de las modalidades discursivas. Las pantallas comenzaron a estar en todos lados y su implantación fue variando según las necesidades del lugar en relación al rubro. Los años noventa se podrían marcar como el momento de explosión de las pantallas en los lugares públicos. Urresti (1997) señala a este fenómeno como pantallización, y si bien el autor lo relaciona con la llegada de las pantallas a los lugares bailables, describe cómo la monotonía de la rutina de los espacios deja lugar para la introducción de las pantallas que aportaban a su público la posibilidad de estar de frente a ésta incluso cuando el relato que emite la misma sea incomprensible por fuera de ese contexto. El cuerpo comienza a visualizarse en diferentes soportes evocando diferentes sentidos sin seguir la linealidad propia de la sociedad tradicional. A esta distorsión o nueva comprensión de este fenómeno se suma la noción de virtualidad. "Una parte cada vez más numerosa de la humanidad vive su tiempo fuera de unas coordenadas espacio-temporales territorializadas, inmersa en grados distintos de virtualización efectiva" (Alberich i Pascual, 2004, p. 59) La virtualidad comienza a comprenderse como un lugar posible que designa entidades desvinculadas de una única actualización, admitiendo manifestaciones en múltiples formas gracias a su capacidad de actualizarse en cualquier nodo del espacio informático dotado de conectividad (Klein, 2007). El cuerpo comienza a pensarse bajo esta lógica, por ende se comienza a entender con características posibles de actuar en espacios desterritorizados que no exigen linealidad alguna. Por lo tanto, si el cuerpo se construye en relación al espacio, bajo este paradigma podría prescindirse de éste bajo las características que posee "en la realidad", y constituirse virtualmente. La incorporación del bit, posibilita que el cuerpo se vea intervenido de diferentes maneras: se compone, se fragmenta, se arma y desarma: obtiene animosidad a través de la interface informática. La escena ciber contiene y nutre a un cuerpo virtual. Entonces, si bien las pantallas parecieran ser las mismas, el bit, como unidad de información ha permitido la digitalización y por ende manipulación de las imágenes que éstas se proyecten.

\section{De cuerpos y producciones}

El número primero de Para Ti Colecciones presenta 33 producciones fotográficas que, en su mayoría, son fotos realizadas en locaciones montadas en interiores, y el cuerpo predomina como eje central como soporte de las prendas que se escogieron, pero puede observarse que como se viene describiendo ya no es necesario describir los detalles constructivos de las prendas, y que esto puede además percibirse perfectamente en las fotografías, ahora la lectora debe comprender el estilo que se construye, por lo tanto si bien la relación cuerpo-prenda es relevante más relevante es la relación cuerpo-prenda/pose en composición según el contexto montado. Tanto las producciones como los avisos parecieran te- 
ner como objetivo vender una actitud, que encajaría con la prenda que se comercializa también. Las poses al evocar una actitud varían según la ocasión, construyen también un discurso fragmentado, en donde pareciera que por último todas las actitudes son moda. El cuerpo respeta la fragmentación que impone la época y éste se muestra acotando una de las características principales que dejó la década de los noventa: la unisexualidad. Si bien el concepto de la construcción del arquetipo femineidad que impera en el imaginario se presenta como base, el cuerpo traduce cierta masculinización, ya no solo se detectan miradas desafiantes, sino que connotan autonomía. La publicación no cambia su política de acotar la relevancia de las imágenes sobre el cuerpo femenino, en contraposición en este caso la silueta masculina aparece $2,8 \%$ en relación a las 500 páginas que tiene el ejemplar. En ninguna de sus apariciones es bajo el rol protagónico, siempre acompaña al cuerpo femenino e incluso no mira a cámara.

\section{Fragmentación del cuerpo, restructuración de su relato}

El modo en el que se manipula el cuerpo en la virtualidad expande el marco de referencia exigiéndole a soportes como los gráficos manipular el cuerpo de la misma forma, de decir que se arma y desarma e incluso, en la relación indivisible de cuerpo-indumentaria, se prescinde de éste. Alberich i Pascual explica sobre este fenómeno que:

...las imágenes de naturaleza electrónica y digital, la distancia entre el referente real comunicativo difundido, se desvanece progresivamente. La realidad por el filtro de los medios de comunicación, se convierte cada vez más en un mundo escenificado, dominado por una lógica de la simulación prácticamente transparente, que no (re) conocemos aún suficiente (Alberich i Pascual, 2004, pp. 56-57).

La fragmentación, armado y desarmando del cuerpo en la gráfica producto de esta lógica sobre la manipulación del el cuerpo en las imágenes digitalizadas permite que se puedan en gráfica prendas sin cuerpo, como puede verse en Para Ti Colecciones, en la sección [pt imprescindibles] dentro del grupo de productos que conforman el estilo que se presenta, como se mencionó, también muestras sobre modelos o los típicos armazones en forma de cuerpo humano, que se usa para probar, arreglar o exhibir prendas de ropa; sino que se muestran las prendas que parecieran estar sobre el cuerpo u maniquí, es decir que la prenda muestra volumen, pero el cuerpo es invisible se simula su presencia real (Ver Figura 2), es decir que es un cuerpo que se ve pero que no está, la prenda se expone sobre el cuerpo virtual. 


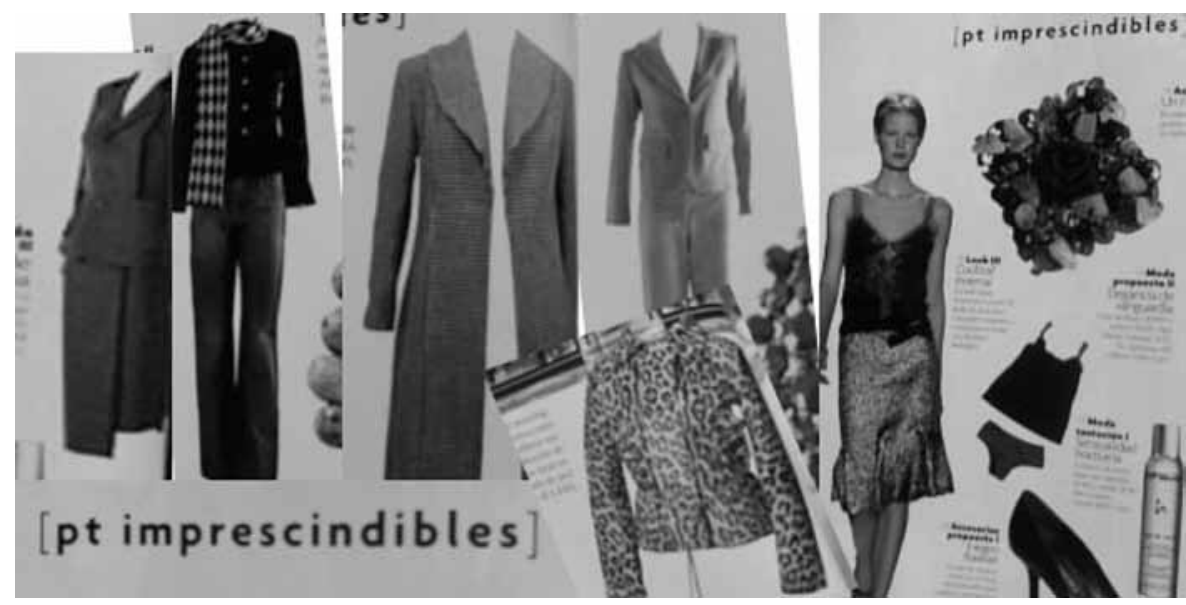

Figura 2. Composición de imágenes de la sección, primera revista Para Ti Colecciones. Fuente. Revista Para Ti Colecciones.

Pero, en esta contemporaneidad en donde el escenario dominado por la lógica de la simulación exacerbada por el bit que agiliza la imagen de la virtualidad, la publicación consigue captar el sentido último de una prenda, que es cuando esta está anclada en el cuerpo a través de una estrategia que remite a las modalidades pedagógicas que las alfabetizaciones posmodernas exigen en este período.

El relato de las modas en gráfica actualmente exige la incorporación del procedimiento que se aplica para la manipulación que sufre la imagen en el internet. Soporte éste que modifica el modo en el que se percibe no solo el relato que se presenta a través del mismo, sino en el modo el que se percibe el mundo. La lógica de la imagen digital impera en el relato que expresa la moda, y exige la unidad del mismo a partir de su fragmentación.

\section{Referencias Bibliográficas}

Alberich i Pascual, J. (2004). El efecto Moebius (Del despliegue y torsiones en la cultura digital), en Sánchez Navarro, J. (2004, ed.) Realidad Virtual: visiones sobre el ciberespacio. España: Sitges.

Barbero, J. M. (2003) Reconfiguraciones comunicativas del saber y del narrar, en La educación desde la comunicación. Bogotá: Grupo Editorial Norma.

(2000). Ensanchando territorios en comunicación/educación, en Valderrama, C. E. (ed.), Comunicación-Educación. Coordenadas, abordajes y travesías. Bogotá: DIUC-Siglo del Hombre. 
Hall, S. (2003). Introducción. ¿Quién necesita identidad?, en Hall, S. y du Gay, P. (comps) Cuestiones de identidad cultural. Amorrortu: Buenos Aires.

Huergo, J. A. (1997). Los modos de relacionar comunicación/educación, en Comunicación /Educación: ámbitos, prácticas y perspectivas. La Plata: Ediciones de Periodismo y Comunicación.

Lannelongue (2008). Las secretos de la moda al descubierto. Barcelona: Editorial Gustavo Gili.

Saulquin, S. (2006). Introducción. Historia de la moda argentina: del miriñaque al diseño de autor. México: Emecé.

Sexe, N. (2007). El vestido en el mundo de la comunicación masiva, en Casos de comunicación y cosas de diseño. Buenos Aires: Ediciones Paidós: estudios de comunicación.

Sibilia, P. (2008). El show del Yo, en La intimidad como espectáculos. Buenos Aires: Fondo de Cultura Económica.

(2005). Biopoder: la privatización de las bipolíticas, en El hombre postorgánico. Cuerpo, subjetividad y tecnologías digitales. Buenos Aires: Fondo de Cultura Económica.

Simone, R. (2001). Intercambiar y recordar conocimientos, en La tercera fase: formas de dase que estamos perdiendo. Madrid: Grupos Santillana.

Sloterdijk, P. (2003). Teoría de los medios de comunicación o: por qué decimos algo y no más bien nada, en Experimentos con uno mismo: Una conversación con Carlos Oliveira. Valencia: Pre-textos.

Tenti Fanfani, E. (2001). El conocimiento escolar, en Sociología de la Educación. Buenos Aires: Universidad Nacional de Quilmes.

Urresti, M. (1997). La discoteca como sistema de exclusión, en Margulis, M. y otros (1997). La cultura de la noche: la vida nocturna de los jóvenes en Buenos Aires. Buenos Aires: Editorial Biblos.

Summary: Technology has changed some aspects of daily life, particularly the way in which knowledge is accessed; in more urbanized areas, the phenomenon occurs through the digital display. A while now, new consumer habits have been installed that have changed the way in which the world is known and reproduced. The subject is relocated from another perspective, changing even the way of perceiving itself. It seems that the body has also begun to be virtualized. The fashion circuit is not out of these changes, and it is through their productions that can identify this phenomenon. This article describes the changes on the representation of the body in fashion local productions through the analysis of Para Ti Colecciones magazine.

Keywords: body - communication - consumption - digital - fashion - on line - photography - production - virtual. 
Resumo: Os avanços tecnológicos modificaram muitos aspectos da vida diária, entre eles, o modo de acesso ao conhecimento; nas cidades, o fenômeno se da através da tela digital. Novos hábitos de consumo variaram o modo de conhecer e reproduzir o mundo. O sujeito se reacomoda desde outra perspectiva, também variou o modo de perceber-se a si mesmo, como se o corpo tem começado a virtualizar-se. O circuito da moda também teve mudanças, e é talvez, através das suas produções, o modo em que melhor pode se ver este fenômeno. O escrito analisa as mudanças que podem se identificar sobre a representação do corpo nas produções de moda locais a partir da análise da revista Para Ti Coleções.

Palavras chave: corpo - comunicação - consumo - digital - fotografia - moda - on-line produção - virtual. 